\title{
Comparative Study of Job Satisfaction between Employees of Virtual Teams and Traditional Teams
}

\author{
Sneha Burman $^{1}$, Shailaja Shastri ${ }^{2}$ \\ ${ }^{1} \mathrm{PhD}$ Research Scholar, Department of Psychology, Jain University, Bangalore, India \\ ${ }^{2}$ Professor and HOD, Department of Psychology, Jain University, Bangalore, India
}

\begin{abstract}
The present study is a comparative study of the Job Satisfaction levels of employees of Virtual teams and Traditional teams. Job Satisfaction is pleasurable emotional state towards their job. It plays a very important role in performance and productivity of an employee in an organization. The sample consisted of 100 IT employees from different software companies of which 50 were from Traditional teams and another 50 from Virtual teams. The obtained data was analyzed using the statistical technique of independent t-test to see the difference between Traditional and Virtual teams on the Job Satisfaction levels. Results indicate that the teams do not differ significantly on their Job Satisfaction levels. Overall job satisfaction is seen higher in virtual team employees than traditional team employees. This study has implications for future research in organizational psychology and socio cultural area.
\end{abstract}

Keywords: Organizational Psychology, Job Satisfaction, Virtual teams, Traditional teams, ITemployees

\section{Introduction}

A teamis a group of individuals who work interdependently for solving the problems and accomplishing tasks (Bell, Kozlowski 2002).

"A new trend in today"s global economy is the increased prevalence of virtual teams (VTs) - individuals collaborating in geographically dispersed work teams who may reside in different time zones and countries" (Horwitz, Bravington, \& Silvis, 2006, p. 472). Virtual project teams in the fast-paced, information technology-driven $21^{\text {st }}$ century represent a new organizational structure as a response to the need for high quality, low-cost, rapid solutions to complex organizational problems. Teams enable organizations to pool the talents and expertise of employees by eliminating time and space barriers (Furst, Reeves, Rosen, \& Blackburn, 2004). Overall, VTs provide organizations with unprecedented levels of flexibility and responsiveness (Powel, Piccoli, \& Ives, 2004).

Virtual team is a group of people who interact through interdependent tasks guided by common purpose that works across space, time, and organizational boundaries with links strengthened by webs of communication technologies (Lipnack and Stamps, 1997). While teams are not a new phenomenon,. Traditional collocated groups are being replaced with virtual teams, distributed across boundaries of time, space and organizational structures.

\section{Review of Literature}

The review of literature points out a lot of studies which are done relating to trust, communication in virtual teams. The studies show that there is problems related to communicating virtually and there is also lack of trust as they do not meet face to face. Due to this there is weaker identification with the team and more conflict and more coordination problems within a team.

Job satisfaction plays a very important role in performance and productivity of an employee in an organization. It is also directly linked to turnover of employees. Research on satisfaction in virtual teams is still sparse.

\section{Methods}

\subsection{Research Design}

The current study is a "Comparative Study" which has been undertaken to investigate differences between virtual and traditional team employees on job satisfaction levels.

\subsection{Research Question}

Based on the review of literature of earlier studies, the current study raises research question, ,Is there any difference between employees of virtual team and traditional team on their job satisfaction levels?

\subsection{Objective}

To study the difference and similarity between employees in virtual and traditional teams on their job satisfaction levels.

\subsection{Hypothesis:}

Hypothesis: There is no difference inJob Satisfaction between employees in virtual and traditional teams.

\subsection{Variables}

Independent: Virtual teams, Traditional teams Dependant: Job Satisfaction

\subsection{Sample and Selection Procedure}

The current study involved total of $\mathbf{1 0 0}$ employees of whom 50 were employees in a virtual team and other 50 employees were in a traditional team of the organization. All the employees were from software companies. Employees who are not working for software companies are not included 


\section{International Journal of Science and Research (IJSR) \\ ISSN (Online): 2319-7064}

Index Copernicus Value (2013): 6.14 | Impact Factor (2014): 5.611

\section{Methodology}

Purposive sampling method has been used to identify employees in each organization in multiple cities. The departments in which they may work vary. It was ensured both male and female employees were a part of the sample. None of the employees were forced to be a part of the study.

The data was collected by twomethods. Some questionnaires were sent to the participants in form of booklet by mail and their responses also received by mail. A prior instruction is given to the participants and if any queries, were answered by the researcher on call. Others were given hard copy of the questionnaire. Accordingly, Scoring of the responses was done according the instructions provided in the manual.

\subsection{Tests Used}

Job Satisfaction: This has been assessed using Job Satisfaction questionnaire developed by David J Weiss, Rene V Dawis, George W England, and Lloyd H Lofquist. (1967)

\subsection{Operational Definitions}

Virtual team: a group of people who interact through interdependent tasks guided by common purpose that works across space, time, and organizational boundaries with links strengthened by webs of communication technologies. ( Lipnack and Stamps, 1997)

Job Satisfaction: It is pleasurable emotional state towards their job; it is a result of employee perception of how well their job provides those things that are viewed as important by the employees. (Locke. 1976)

\subsection{Pre Research Interviews}

Before conducting the research, few pre research interviews of virtual employees was taken by the researcher in order to get a better understanding of the concept of virtual teams and what being a virtual employee is. According to the interviewees there was lack of commitment, work motivation seen in the virtual team employees. Communication is also an issue. It is difficult for employees to discuss problems at abstract level. It thus puts more responsibility on the employees. Stress is more in their case and also difficulty in work life balance. Though they had freedom to work from home, they missed interaction with team members and thus learning from each other. Also even it lessens travelling, some employees enjoy travelling.

\subsection{Statistical Analyses}

The current study would use the following statistical analysis 1. Descriptive Statistics: Mean and Standard Deviations and graphs were used. Percentage was also used whenever required.

2. Inferential Statistics: Independent $t$-test was used to compare the means of the two groupse namely virtual team employees and traditional team employees

\section{Results}

A comparison of employee"s Job Satisfaction was done for virtual teams and traditional teams. This was done to test the Hypothesis which states "there is no difference in Job Satisfaction between employees in virtual teams and traditional teams".

Independent $t$ test was used to analyze the raw scores by testing the significance of difference of means obtained by virtual team employees and the traditional team employees on each of the three dimensions of Job Satisfaction. Results are stated below in the table 1.2

Table 1.2: Shows the Mean, SD and T Values for Different Factors of Job Satisfaction

\begin{tabular}{|c|c|c|c|c|c|c|c|}
\hline \multirow{2}{*}{$\begin{array}{c}\text { Factors job } \\
\text { satisfaction }\end{array}$} & \multicolumn{2}{|c|}{ Traditional team } & \multicolumn{2}{|c|}{ virtual team } & \multirow{2}{*}{ t value } & \multirow{2}{*}{ df } & \multirow{2}{*}{ significance } \\
\cline { 2 - 7 } Ability utilization & $\mathrm{M}$ & $\mathrm{SD}$ & $\mathrm{M}$ & $\mathrm{SD}$ & & & \\
& 17.74 & 3.533 & 19.06 & 3.31 & 1.928 & 98 & 0.057 \\
\cline { 2 - 7 } Achievement & 17.98 & 3.254 & 18.72 & 3.47 & 1.1 & 98 & 0.274 \\
\cline { 2 - 7 } & & & & & 1.1 & 97.599 & 0.274 \\
\hline \multirow{2}{*}{ Activity } & 18.2 & 3.037 & 18.74 & 2.827 & 0.92 & 98 & 0.36 \\
\cline { 2 - 7 } & & & & & 0.92 & 97.501 & 0.36 \\
\hline \multirow{2}{*}{ Advancement } & 16.92 & 3.59 & 18.1 & 3.37 & 1.694 & 98 & 0.093 \\
\cline { 2 - 7 } & & & & & 1.694 & 97.609 & 0.093 \\
\hline \multirow{2}{*}{ Authority } & 17.96 & 2.92 & 18.72 & 2.65 & 1.363 & 98 & 0.176 \\
\cline { 2 - 7 } & & & & & 1.363 & 97.088 & 0.176 \\
\hline \multirow{2}{*}{ Company policies } & 17.32 & 3.395 & 18.26 & 3.349 & 1.394 & 98 & 0.167 \\
\cline { 2 - 7 } Compensation & 15.82 & 3.794 & 16.26 & 4.94 & 0.5 & 98 & 0.619 \\
\cline { 2 - 7 } & & & & & 0.5 & 91.889 & 0.619 \\
\hline \multirow{2}{*}{ Coworkers } & 18.3 & 3.501 & 19.06 & 3.605 & 1.069 & 98 & 0.287 \\
\cline { 2 - 7 } & & & & & 1.069 & 97.916 & 0.288 \\
\hline \multirow{2}{*}{ Creativity } & 18.32 & 3.12 & 18.32 & 3.12 & 0.545 & 98 & 0.587 \\
\cline { 2 - 7 } & & & & & 0.545 & 98 & 0.587 \\
\hline \multirow{2}{*}{ Independence } & 18.02 & 3.261 & 18.32 & 3.229 & 0.462 & 98 & 0.645 \\
\cline { 2 - 7 } & & & & & 0.462 & 97.991 & 0.645 \\
\hline
\end{tabular}




\section{International Journal of Science and Research (IJSR) \\ ISSN (Online): 2319-7064}

Index Copernicus Value (2013): 6.14 | Impact Factor (2014): 5.611

\begin{tabular}{|c|c|c|c|c|c|c|c|}
\multirow{3}{*}{ Moral values } & 18.7 & 2.597 & 19.02 & 3.094 & 0.56 & 98 & 0.577 \\
\cline { 2 - 7 } & & & & & 0.56 & 95.145 & 0.577 \\
\hline \multirow{2}{*}{ Recognition } & 18.2 & 3.429 & 18.7 & 3.512 & 0.72 & 98 & 0.473 \\
\cline { 2 - 7 } & & & & & 0.72 & 97.943 & 0.473 \\
\hline \multirow{2}{*}{ Responsibility } & 18.08 & 2.92 & 18.92 & 3.187 & 1.374 & 98 & 0.172 \\
\cline { 2 - 7 } & & & & & 1.374 & 97.257 & 0.173 \\
\hline \multirow{2}{*}{ Security } & 17.44 & 3.195 & 18.2 & 3.742 & 1.092 & 98 & 0.277 \\
\cline { 2 - 7 } & & & & & 1.092 & 95.657 & 0.277 \\
\hline \multirow{2}{*}{ Social service } & 18.04 & 2.906 & 18.76 & 2.684 & 1.287 & 98 & 0.201 \\
\cline { 2 - 7 } & & & & & 1.287 & 97.388 & 0.201 \\
\hline \multirow{2}{*}{ Social status } & 17.62 & 3.109 & 18.24 & 2.818 & 1.045 & 98 & 0.299 \\
\cline { 2 - 7 } & & & & & 1.045 & 97.066 & 0.299 \\
\hline \multirow{2}{*}{ Supervision hr } & 17.56 & 3.604 & 18.42 & 4.126 & 1.11 & 98 & 0.27 \\
\cline { 2 - 7 } & & & & & 1.11 & 96.257 & 0.27 \\
\hline \multirow{2}{*}{$\begin{array}{c}\text { Supervision } \\
\text { technical }\end{array}$} & 20.3 & 17.779 & 18.46 & 3.638 & 0.717 & 98 & 0.475 \\
\cline { 2 - 7 } & & & & & 0.717 & 53.096 & 0.477 \\
\hline \multirow{2}{*}{ Variety } & 17.72 & 3.277 & 18.48 & 3.259 & 1.163 & 98 & 0.248 \\
\cline { 2 - 7 } & & & & & 1.163 & 97.997 & 0.248 \\
\hline \multirow{2}{*}{ Working conditions } & 18.52 & 3.46 & 19.28 & 3.188 & 1.142 & 98 & 0.256 \\
\cline { 2 - 7 } & & & & & 1.142 & 97.353 & 0.256 \\
\hline
\end{tabular}

Traditional teams score highest in factors of technical supervision and moral values with mean of 20.30 and 18.70 respectively and lowest on factors compensation and advancement with mean of15.82 and 16.92 respectively on job satisfaction scale.

Virtual teams score highest on factors of ability utilization and co workers with mean of 19.06 and 19.06 respectively and lowest on compensation and advancement with a mean of 16.26 and 18.10 respectively on job satisfaction scale.

Based on the $\mathrm{t}$ test, there are no statistically significant differences in any of the factors of Job Satisfaction. However it is noticed that the differences between the scores on ability utilization almost reaches the level of statistical significance. Ability utilization refers to the chance to do something that makes use of abilities on the job, use of skills/talent at workplace. The virtual team has a mean of 19.06 and traditional team has mean of 17.74 on ability utilization area which indicates more chance to make use of abilities is given to employees in virtual teams.

Summary: There is no significant difference between the groups in their job satisfaction levels. Hypothesis which states that there is no difference in Job Satisfaction between employees in Virtual teams and Traditional teams is accepted, as the two groups do not differ significantly on their job satisfaction.

\section{Discussion}

This subsection discusses the difference in the Job Satisfaction levels of employees in virtual and traditional teams. It consists of discussion on 20 kinds of job satisfaction.

To study the difference between the Job Satisfaction of virtual teams and traditional team hypothesis 4 was set which states "There is no difference in Job Satisfaction levels between employees in virtual and traditional teams".
The hypothesis was accepted as the results indicated no significant difference between the Job Satisfaction of the two different teams. The different factors in the Job Satisfaction of the two teams are discussed separately below.

There is some difference seen in the ability utilization factor in the two groups. Ability utilization refers to the chance to do something that makes use of abilities on the job, use of skills/talent at workplace. Virtual team employees score higher on that which indicates that more chance to make use of the abilities is given to employees in virtual teams. This could be attributed to the fact that virtual team employees enjoy more autonomy as they do not meet face to face. Moreover, they have the flexibility in their job which allows them to make use of their talents along with more responsibility.

Traditional teams score highest in factors of technical supervision and moral values and lowest on factors compensation and advancement on job satisfaction scale.

The technical quality of supervision is called the supervision on technical. The traditional team employees derive highest satisfaction from technical supervision which indicates that the technical knowhow of the supervisor, his competence in delegating work and taking decisions at job and how he trains and provides help to employees are important for the employees $^{\text {ee }}$ satisfaction at job. The study by (Durham et al., 1997) supports the findings of the current study that supervisors play an important role in job satisfaction of employees

The traditional team employees also score high on moral values. This means that employees are able to do their job without feeling that it"s morally incorrect. They don et have to go against their beliefs or consciousness while doing their job. The employees do not intend any harm to others and do their work without cheating on anybody. This could be attributed to the fact that they are able to imbibe the organizational culture well and any work done, it's not against the beliefs held by the employees. They are not compelled to do anything which is against their beliefs or 


\section{International Journal of Science and Research (IJSR) \\ ISSN (Online): 2319-7064}

Index Copernicus Value (2013): 6.14 | Impact Factor (2014): 5.611

consciousness which contributes to high satisfaction. Also this increases their morale which is intrinsically satisfying and motivating for the employees.

Traditional team employees score lowest on compensation and advancement factors. Compensation means the remuneration one receives for doing the job. It is the perceived balance of work performed to salary received. The low scores indicate that the employees are not satisfied with the amount they get for the work they do. When they compare the compensation given to other friends and colleagues in their own organization or other organization with similar nature of job, they seem to be unhappy about it.

Advancement is the opportunity for promotion at the job. The low score in this factor indicates that the employees are not satisfied by the way the promotions are given at the job. They see bleak chances of advancement or getting ahead in their job.

Virtual teams score highest on factors of ability utilization and co workers and lowest on compensation and advancement on job satisfaction scale.

Ability utilization is the opportunity to be able to use their skills and ability at work. High score in this factor in virtual team employees indicate that the employees are very satisfied with the kind of work they get to do in their team. They feel it lets them make best use of their skills and abilities and they do what they are best that. This brings about more efficiency at work as the person does what suits him best.

Co worker factor talks about relationship with colleagues and co workers. High score in this factor indicates that among virtual team employees, there is cooperation among the team members. Also they are very friendly in nature, easy to get along with each other. This is supported by a study done by Hall (1994), which states that the workplace presents opportunities for socialization with other people.

Virtual team employees also score lowest in factors of compensation and advancement like traditional team employees which means these factors contribute least in their job satisfaction level.

The result of the current study is found contradictory to pervious findings which emphasizes that money remains the most important motivational strategy (Akintoye, 2000) but in the current study compensation is not found to be a factor contributing to job satisfaction.

Money possesses significant motivating power in as much as it symbolizes intangible goals like security, power, prestige, and a feeling of accomplishment and success. Sinclair, et al. (2005) exhibits the motivational power of money with the process of job choice. They explain that money has the power to attract, retain, and motivate individuals towards higher performance. For instance, if an employee has another job offer, which offers greater financial rewards and has identical job characteristics with his current job, that worker would most probably be motivated to accept the new job offer.

Even if people were principally concerned with their salaries, this does not prove that money is motivating. There is no firm basis for the assumption that paying people more will encourage them to do better work or even, in the long run, more work. As Herzberg (1968) has argued, just because too little money can irritate and de-motivate does not mean that more and more money will bring about increased satisfaction, much less increased motivation. It is reasonable to assume that if someone's take-home pay was cut in half, his or her morale would suffer enough to undermine performance.

To conclude, Virtual teams score highest on factors of ability utilization and co workers and lowest on compensation and advancement on job satisfaction scale. Traditional teams score highest in factors of technical supervision and moral values and lowest on factors compensation and advancement on job satisfaction scale.

\section{Summary and Conclusions}

The objective of the current study was to study the differences and similarities between employees in virtual and traditional teams on their job satisfaction levels. With regard to job satisfaction level there is no significant difference seen between the two teams in any of the 20 factors. However some difference is seen in the ability utilization factor of job satisfaction between two teams. Traditional teams score highest in factors of technical supervision and moral values and lowest on factors compensation and advancement on job satisfaction scale. Virtual teams score highest on factors of ability utilization and co workers and lowest on compensation and advancement on job satisfaction scale.

The Hypothesis States that there is no difference in Job Satisfaction between employees in virtual teams and traditional teams. To test the hypothesis independent $t$ test was applied to see the difference between traditional team employees and virtual team employees. No significant difference is observed between the two teams on their Job Satisfaction level. Hence the hypothesis is accepted.

\section{Future Scope of the Study}

Virtual teams are indispensible now in this globally changing environment, in fact globalization necessitates it. It helps bring human resources and expertise which is geographically distributed together. This concept is only two decade old and very few studies have been done. Hence it is important for us to understand the nature of such teams to maximize its potential. As stated „Less than $30 \%$ of virtual teams are seen to be effective and successful." (Caulat, 2006)

\section{References}

[1] Ahuja, M., D. Galletta, \&Carley, K. (1998). Individual centrality and performance in virtual groups. Working Paper, Florida State University, Tallahassee, FL.

[2] Ahuja, Manju K., et al(2006).Network Structure in Virtual Organizations,Journal of Computer-Mediated Communication Volume 3, Issue

[3] Ardichvili, Alexander, et al (2003).Motivation and barriers to participation in virtual knowledge-sharing communities of practice.Journal of Knowledge Management, Vol. 7 Iss: 1, pp.64 - 77 


\section{International Journal of Science and Research (IJSR) \\ ISSN (Online): 2319-7064}

Index Copernicus Value (2013): 6.14 | Impact Factor (2014): 5.611

[4] Bell, B. S., \& Kozlowski, S. W. J. (2002). A typology of virtual teams: implications for effective leadership. Group and Organization Management, 27(1), 14-49.

[5] Bell, B. S., \& Kozlowski, S. W. J. (2002). Goal orientation and ability: Interactive effects on selfefficacy, performance, and knowledge. Journal of Applied Psychology, 87, 497-505.

[6] Byrne, John A. (Feb 8, 1993). The Virtual Corporation, New York, Cover story, Business week, 3304, 989-102

[7] Cascio, W. F. (2000). Managing a virtual workplace. The Academy of Management Executive, August, 81-90.

[8] Caulat, G. (2006). Virtual leadership. The Ashridge Journal.

[9] Deborah, L. Duarte et al (Jan-Feb 2000). "Mastering virtual teams: strategies, tools, and techniques" Valley, K. The Electronic Negotiator, Harvard Business Review. Jan -Feb

[10]DeSanctis, Gerardine (1999). Introduction to special issue:Communication Processes for Virtual Organizations. Journal of Computer-Mediated Communication.Volume 3, Issue 4.

[11] Drucker, P. (1988). The coming of the new organization. Harvard Business Review, Jan-Feb, 45-53.

[12] Fisher, K. and Fisher, M.(1998).The distributed mind. New York: American Management Association.

[13] Horchschild, A.R., (1997). The time bind: when work becomes home and home becomes work.

[14] Horwitz, F, (2006). The promise of virtual teams: Identifying key factors in effectiveness and failure. Journal of European Industrial Training, 30, 472-494.

[15] Kirkman, B. L., \& Mathieu, J. E. (2004). The role of virtuality in work team effectiveness. Academy of Management Best Conference Paper, OB, L1-L6.

[16] Kirkman, B.L. et al (2002). Five challenges to virtual team success: Lessons from Sabre Inc. Academy of Management Executive, 16(3), 67-79.1

[17] Lipnack, J. and Stamps, J. (1997). Virtual teams. New York: John Wiley and Sons, Inc.

[18] Lipnack, J. and Stamps, J. (1999). Virtual teams: The new way to go. Strategy and Leadership, Jan/Feb, 14-19.

[19] Lipnack, J. Stamps, J. (1997). Virtual Teams: Reaching across space, time and organization. Somerset, N.J. John Wiley Publishers

[20] Meyer, J. P. et al (2002). Affective, continuance and normative commitment to the organization: A metaanalysis of antecedents, correlates, and consequences. Journal of Vocational Behavior, 61, 20-52.

[21] Primm, D. (2005). What Workplace Stress Research is Telling technical communications, Technical Communication 52(2005)449-455;

[22] Wiess, J. Dawis, V. Rene, England, W. Goerge, and Lofquist, H. Llyod, (1967). Manual for the Minnesota satisfaction questionnaire. The work adjustment project Industrial relations center, University of Minnesota.

\section{Author Profile}

Ms. Sneha Burman received a BA in Psychology, English and Journalism Mount Carmel College, Bangalore and an M. Sc in Organizational Psychology from Jain University, Bangalore in year 2009 and 2011 respectively. She completed her M. Phil in Organizational Psychology from Jain University itself in the year 2012.Currently she is a PhD Research Scholar in Jain University, Bangalore
Dr. Shailaja Shastri is a Research Guide, Professor and Head, Department of Postgraduate and Research Studies in Psychology at Jain University, Bangalore, India. 